\title{
Factors of Project ManagerSuccess
}

\section{Raafat George Saadé, Heliu Dong, and James Wan John Molson School of Business, Concordia University, Montreal, Canada}

\author{
raafat.saade@concordia.ca; mheliudong199766@gmail.com; \\ jwan@icao.int
}

\begin{abstract}
This research seeks to analyse the project success factors related to project managers' traits. The context of the research entails a 'United Nations' type of organization. Critical success factors from previous recent studies were adopted for this research. Nineteen factors were adopted and a survey methodology approach was followed. Sixty six participants completed the survey. Exploratory factor analysis results revealed the existence of two constructs: project manager engagement, and project manager certification. The total number of factors representing these two constructs after the factor reduction exercise is nine. Our findings indicate that the capacity for a project manager to communicate and lobby for the project to create and sustain positive perceptions, is the most important factor; whereas project manager credentials are viewed as not important for his/her success. The results may seem counter-intuitive, however, in the context of United Nations Organizations, consideration of their political, cultural and international nature reveals that the results apply.
\end{abstract}

Keywords: Project Manager, United Nations, Critical Success Factors.

\section{Introduction}

There is an increasing importance placed on the role project managers on the success of projects. This is due to a growing recognition that no two projects are alike within and across organizations. As such, these projects require different approaches to their management (Crawford, 2005), and consequently the requirements for project managers entail appropriate competencies, skills and personality traits (Crawford, 2005; Müller \& Jugdev, 2012; Müller \& Turner, 2007).

With increasing globalization causing a rapidly changing world, the project management approach was instituted by a number of organizations primarily the Project Management Institute (PMI $\left.{ }^{\circledR}\right)$ (PMI, 2009 and PRINCE2 ${ }^{\circledR}$ (PRoject IN Controlled Environments, version 2). These

Material published as part of this publication, either on-line or in print, is copyrighted by the Informing Science Institute. Permission to make digital or paper copy of part or all of these works for personal or classroom use is granted without fee provided that the copies are not made or distributed for profit or commercial advantage AND that copies 1) bear this notice in full and 2) give the full citation on the first page. It is permissible to abstract these works so long as credit is given. To copy in all other cases or to republish or to post on a server or to redistribute to lists requires specific permission and payment of a fee. Contact Publisher@,InformingScience.org to request redistribution permission. organizations developed standards for project management and industry specific versions to its body of knowledge. In addition, the international project management association (IPMA) produced national specific versions of its body of competence (International Project Management Association [IPMA], 2006).

While we recognize the necessity for different management approaches, the 
literature by and large studies critical success factors across a wide range of categories namely project success (Gefen, Gefen, \& Carmel, 2015; Gemünden, 2015; Hyväri, I., 2006; Mir \& Pinnington, 2014; Müller \& Jugdev, 2012; Serrador \& Pinto, 2015; Wright \& Adviser-Gottwald, 2013,) and failure (Pinto, 1990; Sage, Dainty \& Brookes, 2014; Shepherd, 2014), project management, project managers (Achee, 2012; Keil, Lee, \& Deng, 2013; Yang, H,uang \& Wu, 2011), organization, and team management (Khalil \& Fernandez, 2013, Söderlund \& Müller, 2014, Svejvig \& Andersen, 2015), but the question of the critical success factors related to project managers in a different organizational context such as that of the United Nations (UN) is scarce and tangentially addressed. Müller and Turner (2007) emphasize the project manager role in identifying the relevant success criteria, consequently leading to those increasing the chance of success. They also elaborated on studies that develop a categorization system that may help identify appropriate methodologies for projects, however it seems that these studies offer no guidance on how the project manager will do that.

Considering (1) that research on project managers is relatively little and (2) within the context of United Nations studies are scarce, and (3) to complement as well as to strengthen other research that categorize critical success factors associated to the selection of project managers with appropriate competencies, we conducted our study to focus on:

- The applicability of reported project managers critical success factors to the UN type of organization and

- Which success criteria are relevant for project managers

Insight into these questions will help organizations and project sponsors to determine the important parameters for the selection of project managers and which criteria to emphasize so that the chances of project success is increased and risks are decreased.

This paper therefore, reports the results of our study that focuses on project manager's factors of success in the context of the United Nations. After we overview the literature on critical success factors in general, in the next section we present the methodology of this study followed by the results leading to a consolidated set of project manager critical success factors composing two constructs. We then provide a discussion of the results followed by a discussion of the limitations of our research and recommendation for future studies.

\section{Project Management Critical Success Factor}

In this study we examined the literature related to critical factors for project success. From the studies we reviewed, the project management issues (can be viewed as categories as well) that were addressed in the literature are (a) evolution of project management, (b) factors of success core to business function, and (c) style of leadership. In the body of research that we reviewed, it was evident that an ongoing attempt is made to explain the various dimensions/factors of success/failure that influence project outcomes. This is most probably due to a large amount of literature reporting that a quite significant percentage of projects across different organizations are not completed on time or are over budget. Despite that some projects were completed on time and within allocated budget, many from those projects reported that they did not meet initial requirements, did not meet management/customer satisfaction, and/or were not aligned with organizational objectives and vision.

Studies reported that $85 \%$ of projects do not meet planned duration and/or budget allocation, with an average overrun of $70 \%$ in planned duration and $60 \%$ in planned budget (Shenhar \& Dvir, $1996 \mathrm{a}, 1996 \mathrm{~b})$. These statistics continue to place increasing pressures on organizations to introduce more project management trainings to their employees and to hiring certified project management professionals. 
Shenhar and Dvir (2007) have studied the relationship of project management and its performance in the fields of technology innovation management, new product development, entrepreneurship, and operation management. Their analysis revealed that very few research works have made an important influence on the discipline and practice of project management and therefore directly implicating project managers. They consolidated their findings into three primary views of what project management is all about, and which we synthesize here as they impact project manager's role, as follows:

- A project as a sequence of process/structure-oriented activities that have to be managed by the project manager (performed and completed by team members according to plan) Operational/Process

- Projects as an organizational/professional team that the project manager needs lead, coach, and motivate - Team/leadership

- Projects are business-related activities that the project manager needs to achieve in terms of project's business results - Strategic/business

Each view is completely different with its own assumptions, uses different metrics of success, and defines the project manager's role in a different way.

Hyväri (2006) also studied the CSFs (Critical Success Factors) as a function of organizational background and compared the results with those of Pinto's (1990). In those studies, a ranking procedure was utilized to make sense of the importance of CSFs. Participants ranked communication, client consultation, and client acceptance as important factors of project manager's ranking in previous studies (Finch, 2003). Moreover, Finch (2003) conclusively showed that project manager leadership was critical to effective project management. It was also found that the most significant critical factors were managerial-related. All recent evidence supports the notion that successful project managers possess a balanced mix of technical abilities, management knowledge, and leadership skills.

These results support the findings in Hyväri's (2006) study in that the relationships with project success factors and organizational background variables were found to be communication, client, and end-user commitment.

\section{Methodology}

An exploratory factor analysis (EFA) approach was followed to test the validity of the critical success factors of project managers. At the same time, and as an outcome the EFA, we aim to identify the constructs defining the relevant successful project manager dimensions. The EFA mathematical criteria were used to create factor models from the data. It simplifies the structure of the data by grouping together observed factors that are inter-correlated under one "common" construct. Prior to the presentation of the EFA approach and results, we invest in describing the context of the study (which merits the treatment because of its complex nature), the survey methodology and process including participants and procedure and the questionnaire used.

\section{Context of Study}

This study was conducted onsite in a UN agency (which we will refer to as 'The UN Organization - UNO). Due to the proliferation of the project management approach in many organizations and the maturation of project management as an academic and best practice discipline, PRINCE2 ${ }^{\circledR}$ (in comparison to PMI and IPMA) was successfully introduced in the public sector and, more importantly to this study, was widely adopted in a number of UN agencies, including the present one which participated in this study. As one of UN agencies, the UNO embarked in a project management approach initiative and started to implement PRINCE2 ${ }^{\circledR}$ training within the 
section of information and communications technologies (ICT) as the standard methodology and daily practice for project management.

To date, over 200 people in UNO have been trained in PRINCE2 ${ }^{\circledR}$ with over 170 who have achieved certification at the Foundation or Practitioner level. To support the implementation of PRINCE2 ${ }^{\circledR}$, an organizational wide Project Management Committee (PMC) was established in 2012. The role of the PMC is to guide project teams with policies, procedures in the preparation and reviews of project documentation, and provide advice on project management and PRINCE2 ${ }^{\circledR}$ best practices. Compared with some other project management methodologies such as the Project Management Professional certification, PMP ${ }^{\circledR}$, the UNO made the decision to

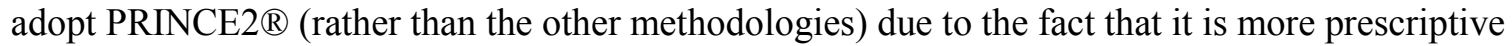
in its definition of roles and responsibilities and more suitable for satisfying complex environments. The UNO's decision was based on the trust and belief that PRINCE2 ${ }^{\circledR}$ will help staff perform better in their project roles and make projects more successful. With that in mind, it was expected by administration and managers that the standardized definition of roles and responsibilities and governance will considerably reduce churning behaviors, unproductive discussions, and arguments throughout the project life cycle. The standardized definitions was thought to bring a common clarity to all stakeholders across departments.

Within six months of training, the information communications technology (ICT) staff were able to adapt how PRINCE2 ${ }^{\circledR}$ can be applied to improve project management effectiveness and had started to turn PRINCE2 $\AA$ methodology into practice. There were growing awareness and posi-

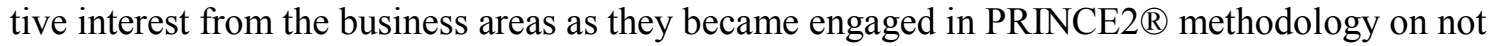
only ICT related projects, but also the development of business programs. A major outcome of this transformation due to PRINCE2 ${ }^{\circledR}$ training was the notion of 'inclusiveness', where 'no stakeholder' was left out.

Nevertheless, with the growing interest in and practice of PRINCE2 $\AA$ training, and a relatively modest measurable success in IT type projects, difficulties persisted. The fact remains, in the United Nations context, that the nature of all projects are intra-organizational, involving the engagement of varous stakeholders from member states necessity for collaboration, and with strong challenging factors such as cultural differences (leadership style, power perceptions, political associations, etc...), language barrier (effective communication), political environment (commitment), and priority of interest (strategic objective). These challenges, inherent in the UNO system, were found to be a handicap to the process of project management, resulting in project managers becoming (or at least feeling) powerless in moving the project forward, as planned. This is true even with a senior, well-trained, certified project manager. This contextual condition at UNO begs the question: What value does PRINCE2® have for the UN project manager? This is the central theme of this research study, and we will attempt to address this question by idenfying the relevant factors.

\section{Survey and Procedures}

This study utilizes the studies of Hyväri (2006) and Starkweather and Stevenson (2011) and adopts the results (qualitative, quantitative, and descriptive case studies) as the basis to build the present study's survey and data collection. In Hyväri (2006), the top three most ranked factors were treated as critical success factors and in conjunction with the results from previous studies (Pinto \& Slevin, 1987; Starkweather \& Stevenson, 2011), and we identified and used the top five most ranked factors (highlighted in Table 1). Altogether, we extracted nineteen items to form a survey that would meet the goals of our research question. To test the validity of the survey, it was sent to five ICT project managers from three departments. Their responses were used to improve the final set of items. The survey was administered to eighty-seven ICT executives, project managers, project team members, and hiring managers, asking them through a 5-point Likert 
scale ( 5 being most important, 3 is irrelevant, and 1 being extremely unimportant) to answer the questions to the best of their knowledge. Additionally, participants were also asked to rank the relative importance of each critical success factor, by rating the top three from 1 to 3 . Sixty six participants each returned a completed and usable survey, giving a successful return rate of $76 \%$, which is very acceptable.

The survey was administered using Microsoft Excel, where each item was listed on a separate row followed by the liket scale assessment of important and then space to rank that item. Once the surveys were completed, the data within were then imported to SPSS statistical software. SPSS was the tool we selected to conduct reliability and regression analysis. Our analysis made use of both Quantitative and Qualitative analysis for explanation.

\section{Table 1: List of factors utilized in the survey study}

\begin{tabular}{|rl|}
\hline Success Factors related to Project Manager \\
\hline 1. & Ability to communicate at multiple levels \\
\hline 2. & Ability to deal with ambiguity and change \\
\hline 3. & Ability to escalate \\
\hline 4. & Working attitude \\
\hline 5. & Cultural fit \\
\hline 6. & Education \\
\hline 7. & Effective leadership \\
\hline 8. & Length of prior engagements \\
\hline 9. & Past team size managed \\
\hline 10. & PMP or PRINCE2 certification credential \\
\hline 11. & PMP or PRINCE2 trained \\
\hline 12. & Technical knowledge and hands-on experience \\
\hline 13. & Work history \\
\hline 14. & Effective verbal communication \\
\hline 15. & Written skills \\
\hline 16. & Commitment to the project \\
\hline 17. & Ability to coordinate \\
\hline 18. & Situational management \\
\hline 19. & Competence \\
\hline
\end{tabular}

\section{Research Findings, Analysis and Discussion}

\section{Research Findings}

Item Analysis: Mean and standard deviation statistics were performed on the nineteen factors/items considered in this study, given in Table 1. An important factor with the highest mean and lowest standard deviation is "Ability to communicate at multiple levels". Looking at the lowest rated factor/item, "Length of prior engagements" tell us that participants were close to 50:50 split on its importance rendering it a useless measure. It was also found that certification creden- 
tials (item 10) and training of project managers (item 11) to be close to irrelevant, which is surprisingly contrary to the theoretical development and previous research elaborated in the previous sections herein.

A number of exploratory factor analyses (EFA) with different configuration parameters were done to optimize our ability to interpret the loadings. From the EFA we found that Engagement Traits, Education, and Experience are three "project manager" constructs that need to be considered for project success analysis. Further analysis reduced the 19 items into 12 items. The final set of items for the three constructs are shown in Table 9, with a total of twelve items of which six loaded on engagement, four on education, and two on experience.

\section{Descriptive Analysis}

The surveys were sent by email. Participants completed the survey using MS Excel and returned it by email as well. A total of eighty seven project managers participated resulting in a data sample containing eighty seven data sets. The participants' sample represented the following (see Figure 1):

- $32 \%$ were female and $68 \%$ male;

- $58 \%$ of the participants were neither certified nor trained;

- Only 4 out of 66 (about 6\%) were PMP certified while 32\% were PRINCE2 certified;

- There were more than double who were PRINCE2 trained than PMP

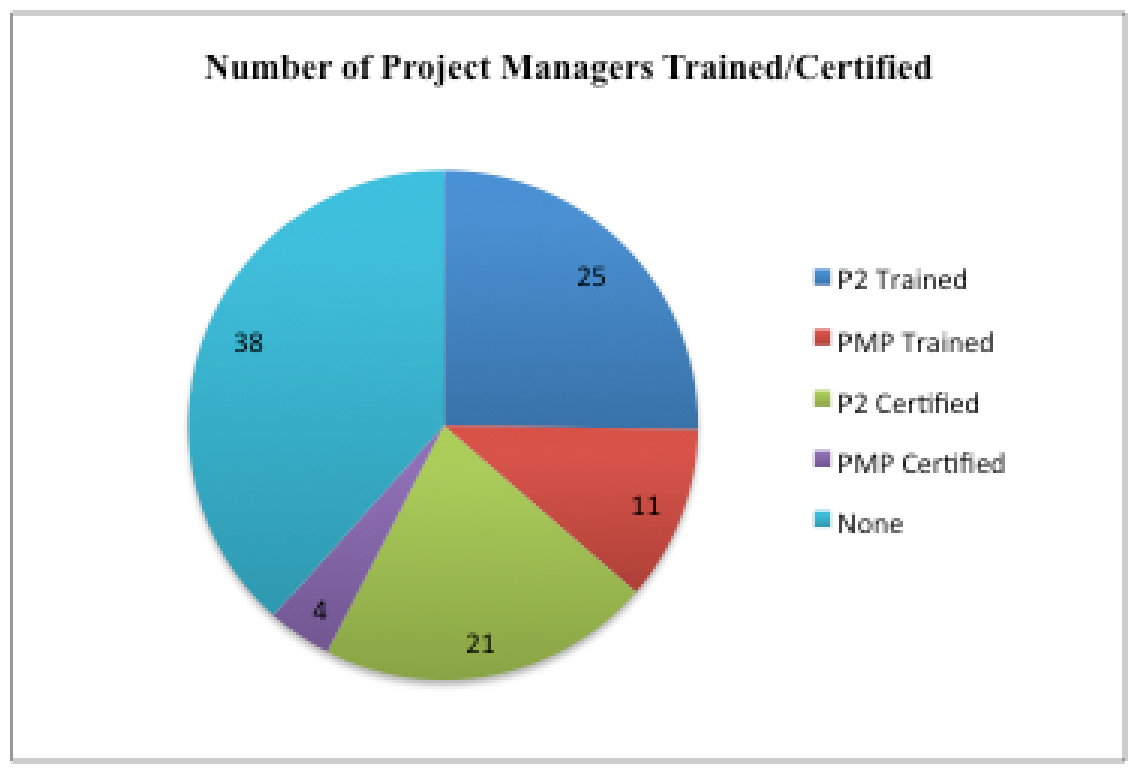

Figure 1: Project managers trained/certified

Table 2 presents the descriptive statistics (namely mean and standard deviation) of the nineteen factors/items considered in this study. We draw attention to the factors with highest and lowest means (identified in bold) and to the certification/training (identified in italics). An important factor with the highest mean and lowest standard deviation is "Ability to communicate at multiple levels", with values of 4.5 and 0.7 respectively. This tells us that there seems to be a strong concensus on the project manager's requirement to have excellent communication skills and who is able to talk to different stakeholders, internal and external to the organization, while at the same time, have the skills to engage with internal stakeholders, horizontally and vertically. Based on this, the notion of communication as an integral function of a project manager's success in the UNO is emphasized. 
Looking at the lowest rated factor/item, "Length of prior engagements" has a mean value of 2.7 (close to 50:50 split on its importance rendering it a useless measure) with the second highest standard deviation of 1.0 .

Table 2: Items descriptive statistics

\begin{tabular}{|c|c|c|}
\hline \multirow[b]{2}{*}{ Success Factors } & \multicolumn{2}{|c|}{$\begin{array}{l}\text { Respondents } \\
(\mathrm{N}=66)\end{array}$} \\
\hline & Mean & SD \\
\hline \multicolumn{3}{|l|}{ Success Factors related to Project Managers } \\
\hline 1. Ability to communicate at multiple levels & 4.5 & 0.7 \\
\hline 2. Ability to deal with ambiguity and change & 4.0 & 0.9 \\
\hline 3. Ability to escalate & 3.3 & 0.9 \\
\hline 4. Working Attitude & 3.8 & 0.8 \\
\hline 5. Cultural fit & 3.2 & 0.9 \\
\hline 6. Education & 3.2 & 0.9 \\
\hline 7. Effective Leadership & 4.2 & 0.9 \\
\hline 8. Length of prior engagements & 2.7 & 1.0 \\
\hline 9. Past team size managed & 2.8 & 0.8 \\
\hline 10. PMP or PRINCE2 certification credential & 2.8 & 1.1 \\
\hline 11. PMP or PRINCE2 trained & 3.0 & 1.2 \\
\hline 12. Technical knowledge and hands-on experience & 4.0 & 0.8 \\
\hline 13. Work history & 3.3 & 0.8 \\
\hline 14. Effective verbal communication & 3.8 & 0.7 \\
\hline 15. Written skills & 3.5 & 0.9 \\
\hline 16. Commitment to the project & 4.2 & 0.8 \\
\hline 17. Ability to coordinate & 4.3 & 0.8 \\
\hline 18. Situational management & 3.5 & 0.7 \\
\hline 19. Competence & 4.3 & 0.8 \\
\hline
\end{tabular}

(5 = most important, $3=$ irrelevant, and $1=$ extremely unimportant $)$

Table 2 also reveals certification credentials (item 10) and training of project managers (item 11) to be close to irrelevant, which is surprisingly contrary to the theoretical development and previous research elaborated in the previous sections herein. Could this be a reaction to the organization's pressure for the adoption of the project management approach? Is this a symptom/sign that there lurks something more sinister in the organization's culture? Regardless, there definitely seems to be some dissatisfaction with the organization's administration to require certification, and this may be simply a natural reaction to performance anxiety.

The interpretation of the Table 2 are supported by the results of number of times a factor was selected as part of the top three most important. Hits in Figure 3 indicate the number of times the factor was selected. By far the top two factors are ability communicate and then to coordinate. Communication is related to the project manager's personality traits and logic abilities (allowing 
$\mathrm{him} /$ her to communicate), which are acquired partly by experience and while coordination is a logistics trait which can be trained and acquired completely through experience.

Table 3: Number of hits from top ranked factors

\begin{tabular}{|c|c|}
\hline Project Managers & Hits \\
\hline Ability to communicate at multiple levels & 33 \\
\hline Ability to coordinate & 30 \\
\hline Effective Leadership & 24 \\
\hline
\end{tabular}

From Table 3, whereas a project managers' critical factors to project success is logic first (communication), then logistics (coordination), the last factor in terms of effective leadership stresses the notion wisdom. This notion points to the fact that project teams, business sponsors, administration and other stakeholders all need someone to believe in - a phenomenon that is "all too human" (Nietzsche \& Hollingdale; 1996). According to Nietzsche, empiricism is the only valid explanation to our experiences and in the present context of our study, how a project and subsequently the project manager will influence our lives. In essence, Nietzsche demonstrates that complex ideas (projects) are formed out of simpler ideas (projects) which themselves and in turn are formed from our impressions (of the organization and business in general) of our environment. This breakdown of structure that Nietzsche argues about, is fundamental to our understanding of project management and project success where the project manager is the central focal point.

\section{Exploratory Factor Analysis}

It is important to choose a proper factor analysis method to conduct the exploratory factor analysis (EFA) effectively. Although principal axis factoring has been the most widely used method in the past, maximum likelihood (ML) has a number of desirable features that make it the currently preferred method for conducting exploratory factor analysis. ML estimation methods have been shown to be robust with mild to moderate departures from normality in generating appropriate factor solution (Boomsma, 1987). It attempts to find the most likely population parameter estimates that produced the observed correlation matrix, assuming that the observed correlation matrix is from a sample drawn from a multivariate normal population (Lawley \& Maxwell, 1962). Therefore in this study, we apply ML in the factor analysis.

First, we performed an initial factor analysis (principle component analysis) to observe the relationship among the factors and their indicators. Subsequent factor analysis were done where we rotated the matrix to improve our ability to interpret the loadings (to maximize the high loading of each observed variable on one factor and minimize the loading on the other factors). We also analyzed the factor eigenvalues (Figure 2). The eigenvalue for a given factor reflects the variance in all the variables, which is accounted for by that factor (Nagpaul, 1999). A critical limit for the eigenvalue is 1.0 such that factors with values above that limit are acceptable. This identifies the number of factors that can be extracted from the items pool. The factors with eigenvalue greater that 1.0 contain acceptable variance among the observed items; those with values less than 1.0 are dropped from the factor solution. 


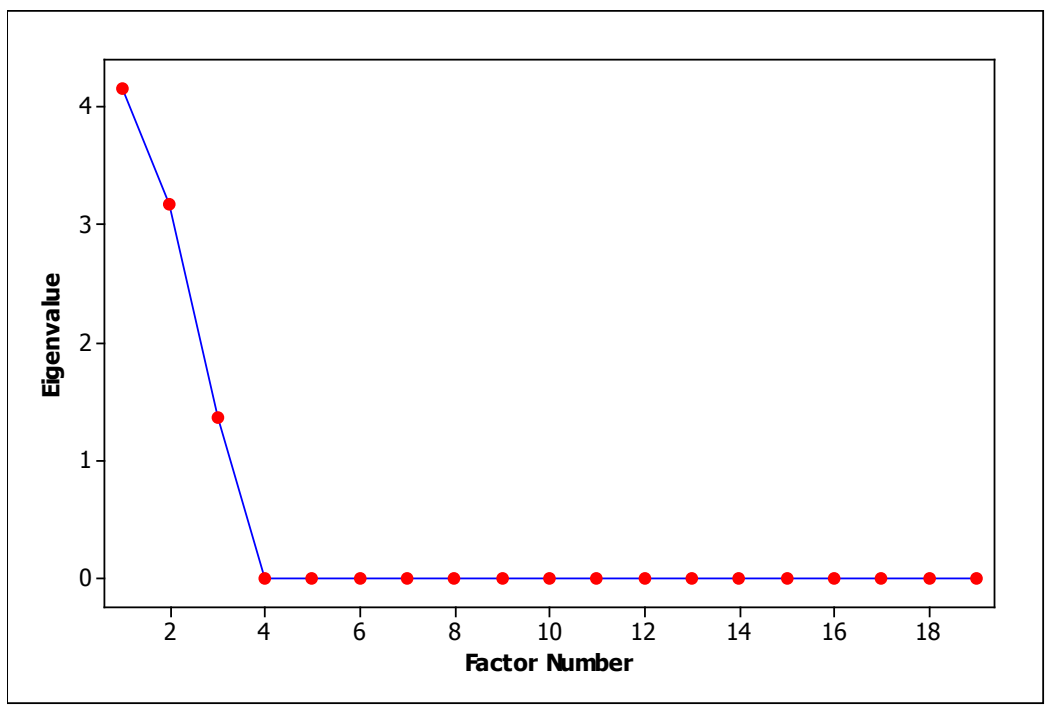

Figure 2: Factor Scree Plot

Analysis of eigenvalues is done by considering a scree-plot. A scree-plot presents the factors possibly extracted from the pool of items and associated eigenvalues. The adequacy of the factors can be determined by examining the scree plot. Factor analysis was performed on the original set of 19 items. After this initial analysis (without rotation) of the eigenvalues followed by a rotation method to get items to be identified more strongly with one or another factor.

There are three basic approaches to rotation including (a) graphic, which is difficult to apply when clustering of variables is unclear or there are more than two factors (Kim \& Mueller, 1978), (b) analytic, which consists of orthogonal and oblique schemes, and (c) rotation to a target matrix, where the researcher has a pattern of relationships already in mind. In this study, we used analytic rotation, as it is the most widely used method. We used orthogonal rotation which tends to maximize the loadings on one factor and minimize the loading on the other factor or factors.

The EFA was performed in three steps: (1) Unrotated on all items, (2) Rotated on all items and (3) Rotated and refined. In step 3, refined implies that we dropped all the items that did not meet the inclusion criteria of loadings below 0.5 . Also, in each step we analyzed the factor matrix, eigenvalues and the scree plot. Here we present the final solution. In the end, 13 items were well defined and loaded on three factors (engagement traints, education, and experience) as shown in Table 4.

Table 4 shows that six items load on factor 1 (Engagement Traits), four on factor 2 (Education) and three on factor 3 (Experience). Based on these results, engagement, education, and experience can be considered as the "project manager" iron triangle (in analogy to the time, money, and quality project management iron triangle).

Researchers in health, social, educational, and engineering sciences attempt to create reliable and valid surveys/questionnaires in order to enhance the accuracy and applicability of the assessment and evaluation methods as well as to provide insight into their practices (processes) and information technologies (tools) used. In the context of this study, critical success factors for project management, PMI body of knowledge, project manager's skills, staff attitudes, project management concepts, and other related issues require some sort of measurement instrument where their reliability constitute one of the two fundamental elements (aside from validity) of their development and use. Whereas validity attempts to assess the extent at which the instrument measure what it is intended to measure, reliability aims to assess the instrument's ability to measure consistently. 
Table 4: Three factors, 13 items final solution

\begin{tabular}{|l|c|c|c|c|}
\hline \multicolumn{1}{|l}{ Variable } & Factor1 & Factor2 & Factor3 & Communality \\
\hline 1. Ability to deal with ambiguity & $\mathbf{0 . 8 1 5}$ & -0.047 & -0.146 & 0.688 \\
\hline 2. Commitment to the project & $\mathbf{0 . 6 3 5}$ & -0.024 & -0.131 & 0.421 \\
\hline 3. Situational management & $\mathbf{0 . 6 0 9}$ & -0.045 & -0.207 & 0.416 \\
\hline 4. Working Attitude & $\mathbf{0 . 5 8 2}$ & 0.076 & -0.245 & 0.404 \\
\hline 5. Effective Leadership & $\mathbf{0 . 5 8 0}$ & -0.248 & -0.065 & 0.402 \\
\hline 6. Effective verbal communication & $\mathbf{0 . 5 6 6}$ & -0.223 & -0.099 & 0.380 \\
\hline Ability to communicate at multi & 0.458 & 0.073 & -0.084 & 0.222 \\
\hline Competence & 0.452 & -0.054 & -0.089 & 0.216 \\
\hline Ability to coordinate & 0.249 & -0.009 & 0.060 & 0.065 \\
\hline 7. PMP or PRINCE2 trained & 0.001 & $\mathbf{- 0 . 9 0 9}$ & -0.161 & 0.853 \\
\hline 8. PMP or PRINCE2 certification cr & -0.174 & $\mathbf{- 0 . 8 2 4}$ & -0.102 & 0.721 \\
\hline 9. Written skills & 0.444 & $\mathbf{- 0 . 6 7 8}$ & -0.018 & 0.657 \\
\hline 10. Education & 0.186 & $\mathbf{- 0 . 5 1 5}$ & -0.426 & 0.481 \\
\hline Cultural fit & 0.284 & -0.440 & -0.415 & 0.446 \\
\hline 11. Length of prior engagements & -0.207 & -0.186 & $\mathbf{- 0 . 8 5 4}$ & 0.807 \\
\hline 12. Past team size managed & -0.053 & -0.431 & $\mathbf{- 0 . 6 9 0}$ & 0.664 \\
\hline 13. Work history & 0.466 & -0.051 & $\mathbf{- 0 . 5 7 0}$ & 0.544 \\
\hline Ability to escalate & 0.183 & -0.080 & -0.488 & 0.277 \\
\hline Technical knowledge and hands-o & 0.027 & 0.000 & -0.186 & 0.035 \\
\hline & & & & \\
\hline Variance & 3.5486 & 2.7852 & 2.3661 & 8.6999 \\
\hline \% Var & 0.187 & 0.147 & 0.125 & 0.458 \\
\hline
\end{tabular}

Table 5: Item statistics for engagement traits construct

\begin{tabular}{|l|l|l|}
\hline Variable & Mean & StDev \\
\hline Ability to communicate at multi & 4.484 & 0.734 \\
\hline Commitment to project & 4.500 & 0.735 \\
\hline Situational management & 3.516 & 0.690 \\
\hline Working Attitude & 3.844 & 0.821 \\
\hline Effective Leadership & 4.172 & 0.865 \\
\hline Effective verbal communication & 3.859 & 0.710 \\
\hline & & \\
\hline Total Count & 64 & \\
\hline Cronbach's Alpha & 0.7812 \\
\hline
\end{tabular}


Reliability needs to be measured first, then validity because for an instrument to be valid, it must be reliable first. The most widely used objective measure of reliability, is the cronbach alpha (Mohsen \& Dennick, 2011). To that effect, we continue our analysis by evaluating the three constructs obtained from the EFA for their reliability. Cronbach alpha for engagement, education and experience are presented in Tables 5, 6 and 7.

Table 6: Item analysis for education construct

\begin{tabular}{|l|c|c|}
\hline Variable & Mean & StDev \\
\hline PMP or PRINCE2 certification cr & 2.794 & 1.065 \\
\hline PMP or PRINCE2 trained & 3.048 & 1.170 \\
\hline Written skills & 3.524 & 0.877 \\
\hline Education & 3.222 & 0.870 \\
\hline Total & 12.587 & 3.261 \\
\hline & & \\
\hline Total Count & $\mathbf{6 3}$ & \\
\hline Cronbach's Alpha & $\mathbf{0 . 8 2 6 0}$ & \\
\hline
\end{tabular}

Table 7: Item analysis for experience construct

\begin{tabular}{|l|l|l|}
\hline Variable & Mean & StDev \\
\hline Length of prior engagements & 2.656 & 1.042 \\
\hline Past team size managed & 2.766 & 0.850 \\
\hline Work history & 3.344 & 0.821 \\
\hline Total & 8.766 & 2.260 \\
\hline & & \\
\hline Total Count & $\mathbf{6 4}$ & \\
\hline Cronbach's Alpha & $\mathbf{0 . 7 7 3 2}$ \\
\hline
\end{tabular}

Cronbach alpha provides a measure of the internal consistency of the scales in an instrument and is expressed as a number ranging from 0 to 1 . Considering as an example the 'engagement traits' of a project manager (Table 5), the Cronbach alpha measures the inter-relatedness of the six items within this construct. In other words, testing for reliability of 'engagement traits' is an estimation of its correlation with itself. Moreover, squaring this correlation and subtracting from 1.0 produces a measure of error. Yet another meaning to the Cronbach alpha can be observed with the fact that the higher the correlation between the items of the same construct, the higher the Cronbach alpha.

Mohsen and Dennick (2011) provide a good review of the reports about the acceptable values of alpha. They report that a Cronbach alpha within the range between 0.70 to 0.95 is acceptable. A low value of alpha may be attributed to a number of reasons including primarily small number of items to represent a construct, poor inter-relatedness between items or heterogeneous constructs.

The Cronbach alpha for the three constructs, engagement, education and experience given in Tables 5,6 , and 7 are $0.78,0.82$, and 0.77 respectively, all of which fall within the acceptable range of 0.7 to 0.95 . A low Chronbach alpha may imply that some items within the construct do not correlate well with each other. In an attempt to enhance the Cronbach alpha, we performed "omit- 
ted item statistics" test for each construct. This test, examins Cronbach alpha by sequentially omitting one item at a time from the set. Any increase in Chronbach alpha would imply that the omitted item did not correlate well with the rest of the item across the same construct. 'Omitted item statistics' tests on engagement and education revealed changes to of the Chronbach alpha by around 1\% which can be considered as insignificant. However, for the Experience construct the 'Omitted item statistics' test showed that the Chronbach alpha increased from 0.77 to 0.83 when 'work history' was omitted, resulting in a 2-item construct (see Table 8).

\section{Table 8: Omitted item statistics}

\begin{tabular}{|c|c|c|c|c|c|}
\hline & & & & \multicolumn{2}{|c|}{ Omitted Item Statistics } \\
\hline & $\begin{array}{l}\text { Adj. } \\
\text { Total }\end{array}$ & $\begin{array}{l}\text { Adj. } \\
\text { Total }\end{array}$ & $\begin{array}{l}\text { Item-Adj. } \\
\text { Total Corr }\end{array}$ & $\begin{array}{l}\text { Squared } \\
\text { Multiple }\end{array}$ & $\begin{array}{l}\text { Cronbach's } \\
\text { Alpha }\end{array}$ \\
\hline Omitted Variable & Mean & StDev & & Corr & \\
\hline Length of prior engagements & 6.109 & 1.438 & 0.6473 & 0.5141 & 0.6501 \\
\hline Past team size managed & 6.000 & 1.563 & 0.7145 & 0.5556 & 0.5715 \\
\hline Work history & 5.422 & 1.753 & 0.4762 & 0.2383 & 0.8332 \\
\hline
\end{tabular}

The final set of items for the three constructs are shown in Table 9, with a total of 12 items of which, 6 loaded on engagement, 4 on education and 2 on experience.

Table 9: Final factor solution

\begin{tabular}{|ll|}
\hline \multicolumn{2}{|l|}{ Variable } \\
\hline \multicolumn{2}{|l|}{ Factor 1: Engagement Traits } \\
\hline $1 . \quad$ Ability to deal with ambiguity \\
\hline $2 . \quad$ Commitment to the project \\
\hline $3 . \quad$ Situational management \\
\hline $4 . \quad$ Working Attitude \\
\hline $5 . \quad$ Effective Leadership \\
\hline 6. & Effective verbal communication \\
\hline & \\
\hline Factor 2: Education \\
\hline 7. & PMP or PRINCE2 trained \\
\hline 8. & PMP or PRINCE2 certification credentials \\
\hline 9. & Written skills \\
\hline 10. & Education \\
\hline & \\
\hline Factor 3: Experience \\
\hline 11. & Length of prior engagements \\
\hline 12. & Past team size managed \\
\hline
\end{tabular}




\section{Discussion}

There seems to be a strong consensus on the project manager's requirement to have excellent communication skills and who is able to talk to different stakeholders, internal and external to the organization, while at the same time have the skills to engage with internal stakeholders, horizontally and vertically. Based on this, the notion of communication as an integral function of a project manager's success in the UNO is emphasized. At the same time, "Length of prior engagements", "Past team size managed", and "Certification" were found to have the lowest mean and highest standard deviation of all items, indicating that project managers in general do not seem to have confidence in the project manager's experiences and certification as measures of success. This outcome can be explained by the fact that the UN and its agencies are highly political organizations where type of projects that a project manager has led as well as certification are much less important than communication, coordination, leadership and commitment. From Table 2, competence also had a high mean, but we feel that in this context, the competence item was understood as the project manager's competence to politically navigate towards the success of the project.

It is interesting to note that certification credentials (item 10 in Table 2) and training of project managers (item 11 in Table 2) are perceived by the respondents to be close to irrelevant. This is surprisingly contrary to the large body of research and trends in practice. This also seems to be an indication of the existence other influencing factors such as political and cultural. Although the $\mathrm{UN}$ and its agencies are requiring project management certification and training, it seems that project managers do not put any significant importance to it. This finding could also be a reaction to the organization's pressure for the adoption of the project management approach. We can interpret those results as symptoms/signs that there are secondary factors of project manager's success embedded in the UN organization's culture. Nevertheless, dissatisfaction with the organization's administration requiring project management certification exists.

Factor analysis performed on the original set of 19 items resulted in the reduction of the items to 12. Six items load on Engagement Traits, four on Education, and three on Experience. In this study we labelled the three factors of engagement, education and experience as the "project manager" iron triangle (in analogy to the project management time, money, and quality iron triangle).

Researchers in all areas attempt to create reliable and valid surveys/questionnaires in order to enhance the accuracy and applicability of assessment and evaluation methods which lead to better tools development practice. In the same vein, our project manager's success factors which represent a measurement instrument require reliability and validity assessment. Reliability and validity analysis resulted in a final three factor twelve items project manager success instrument. This instrument represents the optimum set of factors that need to be considered for the selection of project managers. Although mean analysis of the items (Table 2) conflict with the results of the EFA (Table 9), the utility of the instrument still provides excellent value to practitioners (and opportunities to researchers). Combining these two findings (those present in Tables 2 and 9) resulted in a number of insights.

Considering that two of the authors have extensive project management experience in UN-type of agencies and one has all the certifications, we can confirm that in the present context of the study, engagement traits are the most critical due to the fact that these traits also leverage the project manager's ability to navigate through the complex political and cultural structures. Education is important as far as it applies to written skills and how the project manager's education level is perceived. We found through our experiences that project managers with good writing skills and higher levels of education (masters and $\mathrm{PhD}$ ) have better chances of success. Finally, experience has the least perceived importance in the UN context. 
Summarizing our contributions to the context, the United Nations Organizations are as complex as an organization can be due to its international, cultural, inter-governmental, and political nature. UNOs are extremely slow in terms of transition and change; yet, their adoption of the project management approach to doing business demands faster change and adaptability to environmental pressures primarily IT integration and global economics downturns. As such, and in our UNO context, our results point to two opposing forces contrary to findings in the private sector: (1) project managers should be highly competent in communicating with internal and external stakeholders; and (2) project management credentials and experience is not necessary for successful project managers. It is important to note that one is not a consequent to the other. We are led to believe that a certified project manager is a successful project manager - but this is not the case here. In UNOs, a successful project manager seems to be perceived as one who can lobby, gather support, sustain desirable perceptions of projects and can report (writing skills) effectively project results.

\section{Limitations and Future Research}

We wish to acknowledge the limitations in this study. This study was done in the context of the a United Nation's agency. This is not a limitation but a call to be careful to generalize the results to other type of organizations. At the same time, the sample size was limited, in terms of it being done in one United Nation agency but also in the number of participants. Sample size should be at least expanded in scale to cover a few more UN agencies with a significantly larger number of participants to ensure the reliability of our findings.

In terms of future research, we identify a number of opportunities that are necessary to strengthen the body of knowledge. The body of literature today is weak as it lacks frameworks and models that explain project success. In essence, project management associations have broken down the project management body of knowledge into parts that are perceived to be manageable, where in fact they are not, especially the fact that many researchers agree that project management is hardly ever simple and is in fact always complex. We started by highlighting that the notion of success is not well understood and many definitions have been proposed. Most research work make an attempt to define success under which they anchor their results. Maybe, a more appropriate and adequate quality needs to be identified. Is success really important? What is a successful project manager? There are many cases (and which the first author had observed and even taken part in) where the failure of a project was actually part of the formula for the success of another. We stress the need to depart from the notion of success and to find another quality that measures an expected outcome of a project more effectively.

The constructs that characterize a high quality project manager (and that is how we would like to view a successful project manager) need to be studied further. We make a start in this study, but more constructs need to be explored before a proper and comprehensive factor reduction methodology undertaken to develop a reliable instrument. Last but not least, a covariance analsysis and causal impact analysis of these constructs would provide a more complete understanding on how project managers excel.

\section{Conclusion}

Analysis of the results demonstrate the uniqueness of project management in the United Nations. Results (critical success factors) in the context of this study vary from those identified in the literature which were done in commercial organizations. Previous studies have identified 19 items which they refered to as factors of success for project managers. In comparison, our study treats those factors as items with constitute the factors which in turn we treated as constructs. Although previous studies simply analysed ratings and rankings, we extended our analysis into identifying factors where the items were treated as latent variables. Following exploratory factor analysis 
methodology we identified 3 constructs (factors in terms of our study) defined by latent variables/items (called factors in other studies).

The 19 previously identified CSFs were reduced to 12 items describing 3 constructs for successful project managers: engagement traits, education and experience. These items were tested for their reliability using the Cronbach alpha and all three constructs had values around 0.80 which is acceptable.

The implications to our research work involve researchers, practitioners and organizations. For researchers, we demonstrate the need to extend studies of project management critical success factors into the context of items-constructs structure rather than the typical treatment of factors/variables with simple descriptive statistics for rating and ranking. In effect, we think of our work in this study as a contribution to the body of literature which attempts to identify, analyse, and refine project management constructs (in turn described by latent variables) and their interrelationships towards the understanding of what makes projects successful.

For practitioners, certification has been shown to be only one important asset for the project manager. Our results infer that obtaining certification does not guarantee good project managers. Two other constructs seem to be equally important: (1) engagement traits and (2) experience. The experience construct seems intuitive and straight forward and the two items that explain the construct reveal two dimensions to experience, namely that of time engaged in managing projects and size or scale of projects managed. This is a significant insight as the construct separates between time and size of projects. This implies, for example, that a project manager (irrelevant of the outcome) of 5 small projects with a team of 1 programmer, 1 business analyst and 1 assistant, is not the same as a project manager of 5 multi-million dollar projects with a team of 10 professionals. Experience is under the control of the project manager as he/she can actually plan the type of projects undertaken, for example in increasing complexity.

Moreover, the final set of items found in this study can be integrated into the evaluation of projects and addressed at the end of each project. In that respect, what might be interesting for future research is for practitioners (by collaborating with researchers or not) to gather those data on prior projects and classify them as being a success or a failure. Then to perform logistic regression with a zero (failure) - one (success) dependent variable and predict the probability of success based upon the constructs. Statistically speaking, this would address the possible existence of multicolinearity. It would also provide insight into the importance of the separate constructs and the extent of generalizability. It further might be used to predict the probability of success of future products and give evidence of constructs ( via individual items) that should be improved prior to starting the project.

The engagement construct is more complex as it entails items that fall under two categories: those abilities that are inherent to personality (dealing with ambiguity, effective leadership) and those attributes that can be acquired and learned (the rest). For practitioners, the engagement traits construct require the project manager to undergo reflective practices and pay attention to the organizational environment at the same time. This construct tells the practitioner that he/she should come into terms with the concept of leadership and how they would fit in such a role within their context at the time while at the same time understand the notion of effectiveness. Sensitivity to the relationship with project stakeholders will help them continuously improve on their verbal communication; learning to control their emotions, will help them attain the right attitude; practicing performance management will help them create a situation such that the project is easier to control and navigate; and finally, with all this attention paid to the critical elements of projects and environment will instil a sense of commitment that would come natural.

All these contructs, factors, and items, tell a story of the life of a project manager. Our attempts to assess project managers via the identification of critical elements that we perceive important is 
naïve and static. The literature studies project management in that perspective. This view is very limiting. We must view project managers as evolving dynamic entities that change (internally and externally) and adapt with the changing environment. This is the complexity of project managers doing project management. The problem is as Heraclitus stated: "No man ever steps in the same river twice, for it's not the same river and he's not the same man" - Heraclitus 535 BCE.

For organizations, we feel that the most important element of project management is related to human resources - hence the project manager. Organizations, can use this type of research to establish reliable assessment instrument contributing/supporting to the selection process of project managers most appropriate to their organization and context.

\section{References}

Achee, J. E. (2012). Understanding the factors that affect project managers' development and use of emotional intelligence in managing project stakeholders. Doctoral dissertation, Capella University.

Boomsma, A. (1987). The robustness of maximum likelihood estimation in structural equation models.

Crawford, L. (2005). Senior management perceptions of project management competence. International Journal of Project Management, 23(1), 7-16.

Finch, P. (2003). Applying the Slevin-Pinto project implementation profile to an information systems project. Project Management Journal, 34(3), 32-39.

Gefen, D., Gefen, G., \& Carmel, E. (2015). How project description length and expected duration affect bidding and project success in crowdsourcing software development. Journal of Systems and Software.

Gemünden, H. G. (2015). Success Factors of global new product development programs, the definition of project success, knowledge sharing, and special issues of Project Management Journal ${ }^{\circledR}$. Project Management Journal, 46(1), 2-11.

International Project Management Association. (2006). ICB-IPMA competence baseline version 3.0. International Project Management Association, Nijkerk.

Hyväri, I. (2006). Success of projects in different organizational conditions. Project Management Journal, $37(4), 31-41$.

Keil, M., Lee, H. K., \& Deng, T. (2013). Understanding the most critical skills for managing IT projects: A Delphi study of IT project managers. Information \& Management, 50(7), 398-414.

Khalil, C., \& Fernandez, V. (2013). Agile management practices in a "lightweight" organization: A case study analysis. The Journal of Modern Project Management, 1(1).

Kim, J. O., \& Mueller, C. W. (1978). Introduction to factor analysis: What it is and how to do it (Vol. 13, p. 193). Beverly Hills, CA: Sage.

Lawley, D. N., \& Maxwell, A. E. (1962). Factor analysis as a statistical method. Journal of the Royal Statistical Society. Series D (The Statistician), 12(3), 209-229.

Mir, F. A., \& Pinnington, A. H. (2014). Exploring the value of project management: Linking project management performance and project success. International Journal of Project Management, 32(2), 202217.

Mohsen, T., \& Dennick, R. (2011). Making sense of Cronbach's alpha. International Journal of Medical Education, 2, 53-55.

Müller, R., \& Jugdev, K. (2012). Success factors in projects: Pinto, Slevin, and Prescott - the elucidation of project success. International journal of Managing Projects in Business, 5(4), 757-775.

Müller, R., \& Turner, R. (2007). The influence of project managers on project success criteria and project success by type of project. European Management Journal, 25, 298-309. 
Nagpaul, S. P. (1999). Transnational linkages of Indian science: A structural analysis. Scientometrics, 46(1), 109-140.

Nietzsche, F. \& Hollingdale, R. J. (1996). Nietzsche: Human, all too human: A book for free spirits. Cambridge University Press.

Pinto, J. K. (1990). The causes of project failure. IEEE Xplore, 37(4), 269-276.

Pinto, J. K., \& Slevin, D. P. (1987). Critical success factors in effective project implementation. Project Management Handbook (pp. 479-512).

Project Management Institute. (2009). Project Management Professional (PMP®) credential handbook. Newtown Square, PA.

Sage, D., Dainty, A., \& Brookes, N. (2014). A critical argument in favor of theoretical pluralism: Project failure and the many and varied limitations of project management. International Journal of Project Management, 32(4), 544-555.

Serrador, P., \& Pinto, J. K. (2015). Does Agile work?-A quantitative analysis of agile project success. International Journal of Project Management.

Shenhar, A. J., \& Dvir, D. (1996a). Long term success dimensions in technology-based organizations (Chapter 32). Handbook of technology management. New York: McGraw Hill.

Shenhar, A. J., \& Dvir, D. (1996b). Toward a typological theory of project management. Research policy, 25(4), 607-632.

Shenhar, A. J., \& Dvir, D. (2007). Reinventing project management: The diamond approach to successful growth and innovation. Harvard Business Review Press.

Shepherd, D. A. (2014). Practical Advice to Entrepreneurs Series by ACE Adjunct Professor Dean Shepherd: Practical advice on learning the most from project failure.

Söderlund, J., \& Müller, R. (2014). Project management and organization theory: IRNOP Meets PMJ. Project Management Journal, 45(4), 2-6.

Starkweather, J., \& Stevenson, D. (2011). PMP® certification as a core competency: Necessary but not sufficient. Project Management Journal, 42(1), 31-41.

Svejvig, P., \& Andersen, P. (2015). Rethinking project management: A structured literature review with a critical look at the brave new world. International Journal of Project Management, 33(2), 278-290.

Wright, G. P., \& Adviser-Gottwald, W. D. (2013). Success rates by software development methodology in information technology project management: A quantitative analysis.

Yang, L. R., Huang, C. F., \& Wu, K. S. (2011). The association among project manager's leadership style, teamwork and project success. International Journal of Project Management, 29(3), 258-267. 


\section{Biographies}

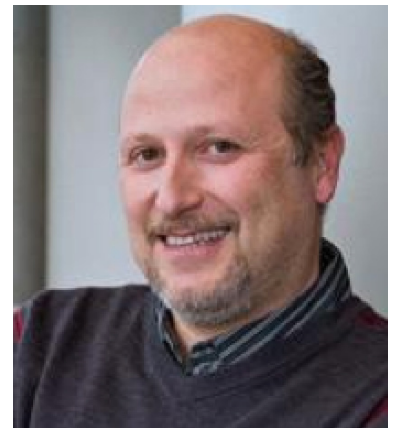

Dr. Raafat George Saadé has been teaching in the Business faculty at Concordia University since 1998. He obtained his Ph.D. in 1995 (Concordia University) after which he received the Canadian National Research Council postdoctoral scholarship, which he completed at McGill University, Montreal. Dr. Saadé has published in journals such as Information \& Management, Decisions Sciences, Expert Systems with Applications, Computers and Human Behavior, and Decision Support Systems. His research is multi-disciplinary as well as inter-disciplinary with research in both theory and applied (Industry consultant since 1993). Dr. Saadé's current work (although evolved over the years) includes information-systems driven change, Information Technology enabled supply chain and change management.

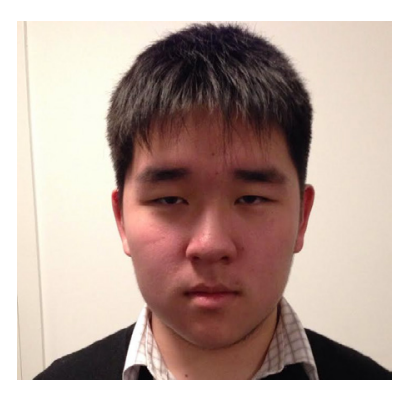

Heliu Dong was a research assistant at Concordia University, Mbtreal. $\mathrm{He}$ is a regular honor roll student who has won an award in Mathematics. Mr. Dong's primary interests in research and practice is in the understanding and use of mathematical knowledge to solve business problems. More specifically, his interests include modern technologies such as Bitcoin, mathematical models, and simulation of stock markets.

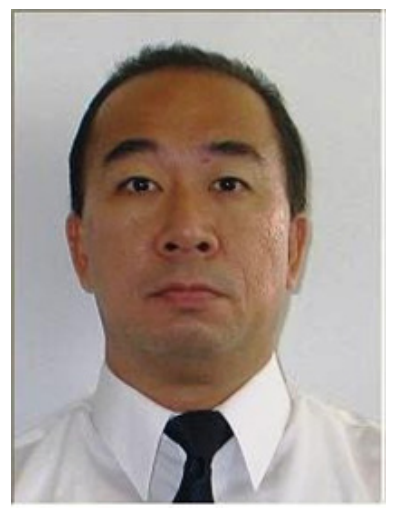

James Wan is CIO \& Deputy Director of Administration and Services at the International Civil Aviation Organization (ICAO), United Nations Specialized Agency. He is also a PhD Candidate at Concordia University, Montreal. Mr. Wan provides policy and technical advice to ICAO senior management group on the acquisition/development, implementation, use and management of information and communication technology systems in a changing business environment. He plans, develops and maintains information and communication applications, systems, strategies, policies, standards, and procedures in response to the business needs of the Organization. His research interest includes project management and organization transition and change. 